\title{
Ética y eudaimonía: la crítica de Bernard Williams a la naturaleza humana en Aristóteles ${ }^{1}$
}

\author{
Ethics and eudaimonia: the critics of Bernard \\ Williams to the human nature in Aristotle
}

\author{
Camilo Andrés Ardila Arévalo ${ }^{2}$ \\ Universidad Libre, Colombia
}

Recepción: 18 de enero del 2018

Evaluación: 9 de abril del 2018

Aceptación: 11 de junio del 2018

\footnotetext{
1 Artículo producto de la reflexión al interior del semillero de investigación en filosofía antigua Méthexis de la Universidad Libre.

2 Abogado y filósofo. MSc. International Political Theory de la Universidad de Edimburgo, miembro del semillero de investigación en filosofía antigua Méthexis de la Universidad Libre.

Correo electrónico: camiloa.ardilaa@unilibrebog.edu.co
}

Ardila, C. (2018). Ética y eudaimonía: la crítica de Bernard Williams a la naturaleza.

Cuestiones de Filosofía, 4 (22), 71-89. 


\title{
Resumen
}

Tradicionalmente, se ha argumentado que el concepto de eudaimonía en Aristóteles se encuentra anclado en el contexto de una comprensión teleológica del universo, por cuanto dicha noción parece radicar en una definición funcionalista de la naturaleza humana. Teniendo esto en mente, Bernard Williams ha desarrollado una crítica en contra de la propuesta ética de Aristóteles, acusándola de una cierta ambición científica en el campo del razonamiento práctico que resulta insostenible actualmente. Este ensayo busca discutir si, en efecto, estos señalamientos tienen un sustento plausible o si, por el contrario, se basan en una interpretación debatible de los fundamentos de la ética aristotélica. Con este propósito, se analiza la justificación del razonamiento ético de Aristóteles a la luz de los argumentos de Williams y de algunos de sus contradictores.

Palabras clave: Naturaleza humana, eudaimonía, razonamiento ético, Aristóteles, Bernard Williams.

\begin{abstract}
Traditionally, it has been argued that the concept of eudaimonia in Aristotle is attached (or linked) in the context of a teleological comprehension of the universe, because such notion seems to lie in a functionalist definition of the human nature. With that in mind, Bernard Williams has developed a critique against the ethical proposal of Aristotle, by accusing it of a degree of scientific ambition in the field of practical reasoning, which is unbearable in these days. This essay tries to discuss whether, those appointments have a plausible argument or if, they are based in a questionable interpretation of the fundaments of the Aristotelian Ethics. With this goal, this essay analyzes the justification of the ethical reasoning of Aristoteles in the light of William's arguments and some of his contradictors.
\end{abstract}

Keywords: Human nature, eudaimonia, ethical reasoning, Aristotle, Bernard Williams. 


\section{Ethique et eudaimonia: la critique de Bernard Williams à la nature humaine chez Aristote}

\section{Résumé}

Traditionnellement, il est argué que le concept d'eudaimonia chez Aristote se trouve ancré dans le contexte d'une compréhension théologique de l'univers, étant donné que ladite notion semble résider dans une définition fonctionnaliste de la nature humaine. Avec ceci à l'esprit, Bernard Williams a développé une critique vis-à-vis de la proposition étique d'Aristote, accusant cette dernière d'une certaine ambition scientifique dans le champ du raisonnement pratique, intenable à l'heure actuelle. Cet essai cherche à examiner si ces assertions ont, en effet, une base plausible, ou si, au contraire, elles s'appuient sur une interprétation discutable des fondements de l'éthique aristotélicienne. Dans cette finalité, cet essai analyse la justification du raisonnement éthique d'Aristote à la lumière des arguments de Williams et certains de ses contradicteurs.

Mots-clés: Nature humaine, eudaimonia, raisonnement éthique, Aristote, Bernard Williams.

\section{Ética e eudaimonía: a crítica de Bernard Williams à natureza humana em Aristóteles}

\section{Resumo}

Tradicionalmente, tem-se argumentado que o conceito de eudaimonía, em Aristóteles, se encontra ancorado no contexto de uma compreensão teleológica do universo, enquanto essa noção tenta radicar na definição funcionalista da natureza humana. Tendo isso em mente, Bernard Williams desenvolveu uma crítica contrária à proposta ética de Aristóteles, acusando-a de uma certa ambição científica no campo do raciocínio prático que é atualmente insustentável. Este ensaio busca discutir se, em efeito, esses apontamentos têm um sustento plausível ou se, ao contrário, baseiam-se na interpretação discutível dos fundamentos da ética aristotélica. Com esse propósito, este ensaio analisa a justificação do raciocínio ético de Aristóteles à luz dos argumentos de Williams e de algumas de suas contradições.

Palavras-chave: Natureza humana, eudaimonia, raciocínio ético, Aristóteles, Bernard Williams. 


\begin{abstract}
"When a man is prepossessed with a high notion of his rank and character in the creation, he will naturally endeavour to act up to it, and will scorn to do a base or vicious action which might sink him below that figure which he makes in his own imagination" (Hume, 1998, p. 44)
\end{abstract}

\title{
Introducción
}

Sin lugar a dudas, el concepto de naturaleza humana constituye una de las ideas más controvertidas hoy en día. Lo anterior se debe a que, a través de la historia, se han venido acumulando diversas aproximaciones que pretenden dar cuenta de lo que en últimas define la dimensión de lo propiamente humano. En este contexto, autores como Max Scheler (1994) y Ernst Cassirer (1963), esforzándose por dar coherencia a la amplia gama de enfoques científicos y filosóficos en relación con el hombre, han evidenciado una gran variedad de perspectivas teóricas alrededor de la naturaleza humana. En este sentido, el espectro de posibilidades parece abarcar aproximaciones clásicas a la naturaleza humana como, por ejemplo, aquella que subyace al análisis político de Hobbes (1996), así como perspectivas contemporáneas a propósito de la construcción histórica y cultural de la noción de humanidad (Foucault, 1999, pp. 57-81). Dichas versiones de la naturaleza humana, además de resultar muchas veces contradictorias entre sí, parecen dar sustento a diversas conclusiones con relación a la forma de vida que debemos llevar como seres humanos (Stevenson \& Haberman, 1998: pp. 3-4). En otras palabras, la discusión acerca lo propiamente humano resulta aún más polémica si se tiene en cuenta que, como bien lo afirma Nussbaum (1995, p. 86), los argumentos frente a la naturaleza humana son frecuentemente utilizados como una plataforma de lanzamiento para defender una serie de conclusiones éticas.

Siendo así las cosas, constantemente se ha considerado que la propuesta ética de Aristóteles también está construida sobre una particular comprensión de lo que son los seres humanos. De acuerdo con esta interpretación, el razonamiento ético de Aristóteles tendría como telón de fondo un concepto del ser humano que determina indefectiblemente el derrotero de su análisis de la vida práctica. Dadas estas circunstancias, Bernard Williams (1929-2003) ha presentado una serie de objeciones alrededor de lo que sería el error central de la mayoría de las filosofías prácticas, incluyendo la propuesta ética de Aristóteles y su estrecho vínculo con la noción de naturaleza humana. 
Siguiendo el razonamiento de Williams, las descripciones aparentemente objetivas y neutrales de lo esencialmente humano resultan ser un frágil punto de partida para defender un argumento práctico en términos contemporáneos, de forma tal que el intento de Aristóteles por establecer un fundamento sólido para su propuesta ética estaría irreversiblemente llamado al fracaso.

En este orden de ideas, pretenderé discutir si las críticas de Williams a los fundamentos de la ética aristotélica resultan o no persuasivas a luz de una interpretación contemporánea de la filosofía práctica del Estagirita. Concretamente, sostendré que la línea discursiva empleada por el autor británico carecería de idoneidad para refutar el razonamiento ético de Aristóteles, puesto que dicha crítica está construida sobre una muy debatible interpretación del concepto de naturaleza humana en el argumento práctico del Estagirita. Para tal fin, esbozaré los fundamentos de la propuesta de Aristóteles por medio de la relación entre la eudaimonía y la noción de naturaleza humana. Posteriormente, reconstruiré los argumentos de Williams que buscan poner en tela de juicio los fundamentos del razonamiento ético del Estagirita, especialmente aquellos esbozados en Ethics and the Limits of Philosophy (2011). Finalmente, presentaré una interpretación contemporánea de la ética aristotélica, defendida principalmente por Martha Nussbaum, que pretende responder a algunas de las críticas de Williams a través de una caracterización evaluativa del concepto de naturaleza humana en Aristóteles. Todo lo anterior permitirá, al final de cuentas, presentar la ética del Estagirita como una aproximación a la vida práctica que conserva vigencia contemporáneamente, en tanto constituye una comprensión razonable del accionar de los seres humanos.

\section{Los fundamentos de la propuesta ética de Aristóteles}

A diferencia de sus escritos en materias propiamente científicas como la física o la biología, la filosofía práctica de Aristóteles, expresada fundamentalmente en sus estudios sobre los asuntos de carácter ético y político, sigue teniendo una notable influencia entre diversos autores del mundo contemporáneo (Sandel, 2011, p. 216). En efecto, puede afirmarse que la propuesta ética de Aristóteles, junto a los enfoques centrados en las consecuencias o en la prescripción deontológica de las acciones humanas, constituye uno de los entramados teóricos más relevantes con respecto a la pregunta por la forma en la que deben actuar las personas en el marco de la vida práctica (Nussbaum, 1993, pp. 242-243). Puede decirse, entonces, que la formulación aristotélica de los problemas prácticos parece perdurar en el tiempo, aun cuando existan 
otras propuestas alternativas más recientes, como el intuicionismo moral de Prichard (1912) o la ética sin principios de Dancy (2004), que abiertamente pretenden tomar distancia de toda tradición en el campo del razonamiento ético o moral.

En términos generales, el discurso ético de Aristóteles se estructura sobre la base de tres nociones capitales: la virtud o excelencia (areté), la sabiduría práctica (phrónesis) y la felicidad o el bienestar de los seres humanos (eudaimonía). Si bien los dos primeros conceptos cumplen un rol central en el análisis aristotélico de la vida práctica, lo cierto es que el razonamiento ético del Estagirita parece descansar esencialmente sobre la idea de que existe un bien último en la vida humana que corresponde al término de eudaimonía (Hursthouse, 1991, p. 226) ${ }^{3}$. Por tal razón, como bien lo señalan Kraut (2016), Berti (2008, pp. 123-124) y Lear (1988, pp. 154 y ss.), el problema central de la filosofía práctica de Aristóteles concierne a la pregunta por la eudaimonía, esto es, por la mejor forma de vida que pueden adoptar los seres humanos en el marco de la vida social ${ }^{4}$.

En el marco de este discurso, Aristóteles emplea el término eudaimonía para designar aquel único bien que elegimos por sí mismo y que resulta autosuficiente para alcanzar nuestra plenitud como seres humanos (Hutchinson, 1995, p. 201). Siguiendo grosso modo el argumento desarrollado en la Ética Nicomáquea (1097a25 y ss.), todas las acciones humanas son llevadas a cabo con el fin de realizar algún propósito, de manera que, por ejemplo, las personas normalmente persiguen bienes como el dinero o el reconocimiento social, al considerar que éstos les permitirán acceder a un estado ulterior de bienestar. Por consiguiente, aquellos objetivos inmediatos no son realmente valiosos en sí mismos ni resultan suficientes para alcanzar la plena satisfacción en la vida humana, sino que, desde el punto de vista aristotélico,

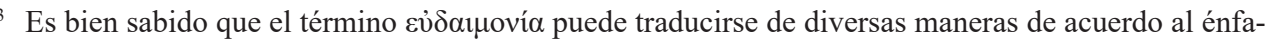
sis semántico que se pretenda hacer. Por ende, el rango de términos empleados en español e inglés abarca conceptos tan disímiles como la felicidad, el bienestar y, más recientemente, el florecimiento humano. En virtud de esta circunstancia, emplearé de forma preferente, aunque no únicamente, el helenismo eudaimonía.

4 En todo caso, cabe aclarar que si bien Aristóteles reconoce al individuo como el objetivo principal del razonamiento ético, lo cierto es que la Ética Nicomáquea (1094b) tiene en cuenta el hecho de que, en virtud de su naturaleza en cuanto ser social, la mejor forma de vida posible para un ser humano se encuentra estrechamente ligada a los propósitos últimos de la organización social y no solamente a los intereses individuales de cada persona.
} 
su realización adquiere un valor instrumental en tanto que contribuyen a la consecución del verdadero bien supremo en la vida práctica que puede ser abarcado a través del término eudaimonía. En otras palabras, el término eudaimonía buscaría, precisamente, designar aquel horizonte de las acciones prácticas cuya realización carece de la importancia instrumental sobre la que se erige la valoración del resto de bienes en la vida humana.

Ahora bien, la propuesta de Aristóteles no parece limitarse a esta caracterización meramente formal de la noción de eudaimonía en el marco del accionar práctico. Por el contrario, como bien ha expuesto McDowell (1998, pp. 12-13), resulta posible distinguir entre el rol que cumple la idea de un bien supremo en la propuesta ética de Aristóteles y el concepto sustancial de eudaimonía defendido por éste. Así pues, aun cuando parece haber un acuerdo generalizado frente a la existencia de un bien supremo en la vida práctica que puede ser denotado a través del concepto de eudaimonía, Aristóteles mismo reconoce que persiste un amplio debate frente a lo que, en últimas, constituye la mejor forma de vida posible. En este punto del pensamiento aristotélico, parece haber una bifurcación entre i) una aproximación más inclusiva al concepto de eudaimonía que involucraría la realización de diversas capacidades por parte de los seres humanos y ii) un entendido más intelectualista que reduce la forma de vida más deseable a la realización de una específica facultad concerniente al uso del intelecto en el marco de la vida contemplativa (Ackrill, 1980, pp. 17-18; Nagel, 1980, pp. 8-13). Cualquiera que sea el caso, resulta claro que Aristóteles abordó directamente el problema de fondo acerca de lo que significa para los seres humanos ese estado último de plenitud, así como una aproximación al rol formal que cumple la eudaimonía en el actuar práctico de los seres humanos.

Sin embargo, cualquier noción sobre la mejor forma de vida para un ser humano no resultaría persuasiva si no estuviera adecuadamente justificada sobre la base de algún argumento sólido. Evidentemente, aunque la gran mayoría de las personas podría aceptar la existencia de un bien último en la vida práctica que sirve de horizonte a las acciones humanas, el contenido específico de lo que se dice -la felicidad o el bienestar en los seres humanos- requiere sustentarse sobre la base de alguna justificación ulterior (Lear, 1988, p. 161; Nussbaum 1995, p. 111). En este punto, los intérpretes más tradicionales de la obra del Estagirita, representados en este caso por Ross (1995, pp. 201 y ss.), han considerado que Aristóteles acude a un argumento de carácter funcionalista para defender su idea de eudaimonía. Conforme a la interpretación 
dada usualmente a este argumento, todas las cosas tienen una función (érgon) preestablecida que permite determinar su naturaleza y las diferencias del resto de entidades, de tal suerte que las personas virtuosas actuarían de manera consistente con la realización de su función natural, encaminándose hacia su felicidad o bienestar como seres humanos (Nagel, 1980, pp. 8-9; Hutchinson, 1995, p. 202).

En este sentido, así como un buen cuchillo es aquel que cumple su propósito natural de cortar o un buen flautista es aquel que cumple con su función al tocar con destreza la flauta, un ser humano que actúa de acuerdo con su finalidad natural se encamina hacia su mejor forma de vida posible. Por tal motivo, el mejor modo de existencia para el hombre no podría agotarse solamente en la vida sensible o biológica que resulta compartida por las plantas o los animales, sino que la eudaimonía supondría el despliegue de esa función especial que caracteriza a los seres humanos en cuanto tales. De ahí que, generalmente, parezca aceptado que Aristóteles estructuró su noción de felicidad o bienestar, y con ello los fundamentos de su propuesta ética, sobre la base de una determinada concepción de la naturaleza humana (Nussbaum, 1995, p. 103). Todo lo anterior parece sugerir, de acuerdo a la interpretación de Williams (2011, pp. 49-50), que el propósito característico de los seres humanos se enmarcaría en un entendimiento más general del universo con base en el cual todas las entidades, incluidos los seres humanos, estarían determinadas naturalmente a desempeñar un propósito específico.

\section{La objeción de Williams a los fundamentos del razonamiento ético en Aristóteles}

A pesar de la importante tradición que parece respaldar esta interpretación de la propuesta ética de Aristóteles, Bernard Williams ha tratado de evidenciar en qué sentido buena parte de las teorías normativas, incluyendo el análisis de los problemas éticos por parte del Estagirita, carecen de una justificación apropiada ab initio. De acuerdo con el argumento esbozado por el filósofo inglés, los intentos por estructurar una respuesta a la pregunta ética o moral parten de una premisa fundamental que él denomina Punto Arquimediano, en adelante PA, de modo que este concepto designaría la piedra de toque al interior de cualquier propuesta relativa al razonamiento ético. En el contexto de la obra del autor británico, el PA de una teoría moral o razonamiento práctico es definido en términos generales como "algo con lo que incluso el amoral o el escéptico están comprometidos, pero que, sopesado apropiadamente, nos 
mostrará que él es irracional o irrazonable o que está en cualquier caso equivocado" (Williams, 2011, p. 33) .

Bajo este entendido, el PA de toda fórmula moral sería aquel presupuesto inicial con el que toda persona más o menos razonable debería estar de acuerdo, ya que dicha premisa constituye el fundamento objetivo e indiscutible sobre el que se erige toda conclusión posterior. En términos de Nussbaum (1995, p. 88), el PA de toda propuesta ética pretendería ser una descripción externa y objetiva de la naturaleza humana que todos, incluso aquellos escépticos y ajenos por completo a toda preocupación alrededor de una vida moralmente deseable, se ven en la necesidad de aceptar como un punto de partida incontrovertible. En estas circunstancias, Bernard Williams afirma que Aristóteles se vale de un argumento de orden externo cuya postulación está impregnada de ciertas ambiciones cosmológicas y científicas a manera de cimiento fundamental para su análisis del razonamiento ético (2011, pp. 49-50). Desde esta perspectiva del asunto, el PA de Aristóteles podría caracterizarse como aquel punto de partida que está más allá de toda consideración ética particular, de modo que, en virtud de su aparente independencia, puede ser aceptado incluso por aquellos que no están comprometidos en modo alguno con el razonamiento moral (Nussbaum, 1995, pp. 121 y ss.).

Conforme a esta línea argumentativa, el PA de la propuesta ética de Aristóteles sería una descripción presuntuosamente absoluta de la naturaleza humana que está dada por una comprensión funcionalista del ser humano. Efectivamente, el argumento defendido por el autor británico señala que el razonamiento aristotélico se construye sobre la base de un intento casi científico de caracterizar a los seres humanos en términos neutrales y objetivos, cuyo telón de fondo sería una visión teleológica del universo, es decir, una comprensión del mundo en la que todas las cosas, incluido el ser humano, tienen un propósito preestablecido e independiente del razonamiento moral (Williams, 2011, p. 49). Solamente así tendría sentido decir que el hombre tiene una función natural e intrínseca que debe ser realizada en el marco de la vida práctica, del mismo modo en que el propósito natural del cuchillo es servir de instrumento para el corte. En pocas palabras, Williams (2011, p. 59) acusa a Aristóteles de haber pretendido extraer sus conclusiones éticas a partir de un ambicioso

\footnotetext{
5 Traducción propia. La noción de Punto Arquimediano en el texto original sería la siguiente: “(...) something to which even the amoralist or the skeptic is committed but which, properly thought through, will show us that he is irrational, or unreasonable, or at any rate mistaken" (Williams, 2011, p. 33).
} 
intento por entender de manera absoluta e indiscutible la naturaleza humana $\mathrm{y}$, con ella, la realización del ser humano en la vida práctica.

Sin embargo, en opinión de este pensador inglés, ese tipo de esfuerzos por definir la naturaleza humana en términos absolutos e indiscutibles serían fácilmente refutables en tiempos contemporáneos. En primer lugar, la perspectiva teleológica y funcionalista del universo, entendida como la atribución de un propósito intrínseco a cada cosa existente, podría considerarse actualmente revaluada ante la opinión científica y filosófica que ha dejado de ver al universo y a los seres humanos como parte de un proyecto de orden general (Williams, 2011, pp. 48 y ss.). Lo anterior se traduce en que, en segundo lugar, una de las características del mundo moderno parece radicar en la postulación de múltiples versiones de la felicidad humana (Williams, 2011, p. 55). Conforme a este punto de vista, por lo tanto, nadie podría decir con total certeza que la forma de vida que lleva, por ejemplo, un académico es más o menos deseable que el curso de existencia que lleva una persona dedicada a labores más técnicas como la carpintería o la ebanistería. De forma tal que cada persona estaría en la posibilidad de llevar a cabo sus acciones prácticas de conformidad con su propia idea de lo que constituye la manera de vida más deseable para un ser humano. En opinión de Richard Rorty al respecto, el desarrollo práctico de la vida humana en el marco de la sociedad contemporánea parece consistir principalmente en:

little more than a consensus that the point of social organization is to let everybody have a chance at selfcreation to the best of his or her abilities, (...) This conviction would not be based on a view about universally shared human ends, human rights, the nature of rationality, the Good for Man, nor anything else. (Rorty, 1989, p. 84)

Así pues, parece difícil afirmar que el despliegue de una forma específica de existencia puede llegar a considerarse como la única manera posible de acceder a una situación de bienestar o felicidad en un contexto tan heterogéneo como el de una sociedad contemporánea. Dicho de otro modo, el mundo moderno parece haber aceptado, en contraposición a la filosofía práctica de Aristóteles, que no existe un propósito inmanente a los seres humanos cuyo fundamento radica en la naturaleza intrínseca de éstos, de modo que, realmente, cada persona buscaría actualmente darse su propio propósito en el marco de la vida práctica (Sandel, 2011, pp. 213 y 218). 
Bajo estas condiciones, parece poco probable, por no decir que imposible, alcanzar una descripción objetiva y neutral alrededor del término eudaimonía, por cuanto toda aproximación definitiva a la naturaleza humana, utilizada como fundamento indiscutible para la comprensión de la mejor forma de vida, estaría desvirtuada prima facie. En consecuencia y como bien lo señala Ackrill (1980, p. 33), al permanecer sin respuesta la pregunta por la naturaleza humana, persiste la ausencia de certeza en torno a la noción de eudaimonía, y cualquier fundamentación del razonamiento ético desde una perspectiva aristotélica parece estar condenada al estruendoso fracaso.

\section{Las debilidades del planteamiento crítico de Bernard Williams}

La construcción del argumento de Williams para refutar los fundamentos de la propuesta ética de Aristóteles se lleva a cabo a través de dos instancias analíticamente discernibles. En efecto, el autor británico interpreta la Ética nicomáquea, por una parte, como un aspecto de la filosofía práctica cuya justificación radica en una descripción objetiva y neutral de la naturaleza humana, constituyéndose así en el PA del razonamiento aristotélico en materia ética. No conforme con esto, Williams, por otra parte, emprende una refutación del PA supuestamente establecido por el Estagirita, considerando que éste emplea una comprensión obsoleta del universo y de los seres humanos que no se corresponde con la visión actualizada de las ciencias y las humanidades. Una vez desarrollado su argumento a través de estos pasos argumentativos, Williams concluye precipitadamente que la justificación sobre la cual se estructura la ética de Aristóteles es un frágil punto de partida que puede ser fácilmente refutado en el mundo contemporáneo.

Ahora bien, aun cuando la línea discursiva empleada en su obra Ethics and the Limits of Philosophy (2011) resulta en principio convincente, lo cierto es que una mirada más detallada del tema parece dejar entrever algunas grietas en la premisa estructural del discurso de Williams. Efectivamente, el verdadero núcleo de la crítica del profesor inglés radica en su interpretación de los fundamentos de la filosofía práctica de Aristóteles, esto es, en la afirmación de que al final de todo proyecto moral siempre subyace una descripción pretendidamente científica e indiscutible de la naturaleza humana que da soporte a las conclusiones presentadas. En estas condiciones, según el diagnóstico de Williams (2011, p. 45), solamente una descripción verdaderamente objetiva y neutral de la naturaleza humana sería la única premisa realmente adecuada para sustentar cualquier propuesta ética o moral, ya que solamente este tipo 
de aproximación podría adquirir el rango universal e incontrovertible que exigiría un buen razonamiento práctico. No obstante, Williams sabe de antemano que ningún intento por describir la naturaleza de los seres humanos puede resultar realmente objetivo y neutral a la luz del mundo contemporáneo, de manera que ninguna teoría ética, incluida la propuesta del Estagirita, podría ser universal e incontrovertible.

\section{El carácter evaluativo de la idea de naturaleza humana en Aristóteles}

A pesar de la aparente contundencia discursiva de Williams, Aristóteles no parece haber intentado formular una descripción neutral y objetiva de la naturaleza humana para justificar su propuesta ética. Autores como Nussbaum (1995, pp. 102 y ss.) y Ackrill (1980, pp. 17-18) sugieren que, por el contrario, una interpretación más elaborada de la obra del Estagirita podría llegar a la conclusión de que los fundamentos del razonamiento aristotélico adquieren un matiz eminentemente evaluativo. Adoptando esta línea argumentativa, la idea de naturaleza humana defendida por Aristóteles parecería tornarse ex profeso en una noción de índole evaluativa que supera con creces la neutralidad y objetividad de una labor meramente descriptiva del universo. Bajo este prisma interpretativo, el pensamiento aristotélico no estaría estructurado realmente sobre la base de un PA, entendido como una descripción absoluta de la naturaleza humana en términos casi científicos, sino que Williams habría reconstruido solamente una interpretación desbordadamente ambiciosa de la propuesta ética de Aristóteles con el fin de refutarla fácilmente.

Diversos intérpretes contemporáneos de la obra aristotélica han venido reconociendo el tono ambiguo que emplea la propuesta ética de Aristóteles para justificar su razonamiento práctico. Según esta consideración, como acertadamente lo indica Ackrill (1980, pp. 17-18), no resulta sencillo determinar si la postulación de la noción de eudaimonía al interior de la Ética Nicomáquea adquiere un matiz descriptivo o uno evaluativo. Siguiendo el razonamiento empleado en la Ética Nicomáquea (1097b30 y ss.), el juicio sobre los elementos constitutivos de la naturaleza humana supone establecer aquellos rasgos que diferencian a los seres humanos de otras formas de vida como los animales o las plantas, de modo que, aun cuando compartamos con éstos un sinnúmero de facultades como la respiración o la reproducción, resulta difícil 
afirmar que una planta o un animal corresponden al concepto de ser humano ${ }^{6}$. Esto significa, por consiguiente, que nuestra comprensión de humanidad está mediada por un juicio de valor que, específicamente, resalta o da especial estima a algunas funciones o rasgos específicos que constituyen el umbral de lo propiamente humano (Nussbaum, 1995, pp. 94). De ahí que parezca plausible afirmar con Nussbaum que la visión de Aristóteles en relación con la naturaleza humana se presenta como parte de un juicio evaluativo relativo a la determinación de aquello que representa en definitiva la dimensión de lo humano.

Dando por sentado que este es el ejercicio mental que se realiza al momento de determinar lo que en últimas caracteriza a los individuos de la especie humana, la idea de naturaleza humana en Aristóteles parecería estar fundada más en un juicio evaluativo que en un intento científico por describir la realidad. Así pues, la naturaleza humana de la que se vale el argumento práctico del Estagirita no existe de manera independiente y prestablecida en la naturaleza, entendida como aquello que resulta completamente ajeno a la intervención voluntaria del hombre (Mill, 1984, p. 377), sino que, precisamente, es el producto de los juicios que normalmente emiten los seres humanos con respecto a aquello que consideran característico de un individuo de la especie humana. De ahí que pueda afirmarse, como lo hace Nussbaum (1995, p. 108), que nuestra valoración acerca de lo que hace a un ser humano diferente de otras formas de vida dependa necesariamente de la capacidad de emitir juicios en términos evaluativos cuya elaboración no encaja precisamente en una simple descripción del universo.

En este orden de ideas, la propuesta ética de Aristóteles no tendría por objetivo establecer un fundamento científico para el análisis de la vida práctica cuya aséptica caracterización resultaría absolutamente inapelable. A propósito de la fundamentación evaluativa del razonamiento aristotélico en asuntos éticos, afirma Nussbaum:

There is no Archimedean point here, no pure access to unsullied 'nature' even, here, human nature-as it is in and of itself. There is just human life as it

\footnotetext{
${ }_{6}$ Como es bien sabido, lo anterior no excluye la posibilidad de que, pese a no corresponder al concepto de ser humano y carecer de algunas funciones cognitivas como la racionalidad práctica o la sociabilidad, otro tipo de seres vivos como los animales puedan ser destinatarios directos de nuestras consideraciones éticas o morales. Al respecto, puede verse con mayor detalle el argumento desarrollado por Nussbaum (2007, pp. 349-350).
} 
is lived. But in life as it is lived, we do find a family of experiences, clustering around certain focuses, which can provide reasonable starting points for cross cultural reflection (1993, p. 264)

Con base en lo anterior, la noción de eudaimonía y el razonamiento ético al interior de la obra aristotélica solamente cobrarían sentido para aquellos que acepten el juicio valorativo realizado en torno a los rasgos centrales de lo propiamente humano. Esta interpretación del problema ético, por tanto, no buscaría ni tampoco podría persuadir objetiva e indiscutiblemente a todo tipo de contradictor o escéptico en relación con el análisis del razonamiento moral (Hurley, 1993, p. 271). De conformidad con este prisma interpretativo, la lectura de Aristóteles en términos prácticos no sería aquella que sostiene la existencia científica e irrefutable de la mejor forma de vida posible para los seres humanos, cuya razón de ser radica en la propia naturaleza del hombre, sino que la propuesta del Estagirita carecería de la ambición que pretende atribuirle Williams en su reconstrucción crítica.

Entonces, si bien Aristóteles se compromete con ciertas pautas específicas con respecto a la forma de entender los conceptos de naturaleza humana y eudaimonía, lo cierto es que no necesariamente afirma que dicha caracterización de los seres humanos constituya un punto de partida irreductible para sustentar la delimitación definitiva del bien supremo en el contexto de la vida práctica. En otras palabras, el Estagirita no formuló un PA como plataforma de lanzamiento para su razonamiento práctico, al menos en los términos científicos e independientes al análisis ético que Williams ácidamente cuestiona. Por el contrario, la visión de la naturaleza humana en Aristóteles tendría un origen evaluativo que resulta interno al razonamiento práctico en sí mismo, por cuanto se construye sobre el supuesto de que los seres humanos gozan de una cierta capacidad valorativa en el marco de la vida práctica. Por consiguiente, la crítica de Williams estaría sustentada en una interpretación problemática y altamente debatible de la noción aristotélica de naturaleza humana.

\section{¿Resulta realmente sostenible una fórmula ética cuyo fundamento sea de orden evaluativo?}

Una vez señalado el error fundamental de Williams, el matiz evaluativo del concepto de naturaleza humana en Aristóteles daría paso a una última objeción desde el punto de vista práctico. De acuerdo con el contraargumento 
desarrollado por Williams (1995), cualquier interpretación evaluativa del concepto de naturaleza humana puede desembocar en una cierta incertidumbre para la vida práctica, toda vez que asumir una definición valorativa de lo propiamente humano podría llevarnos a contradecir algunas de nuestras más arraigadas intuiciones morales. Así, por ejemplo, las personas que carecen de aquellos rasgos normalmente considerados como parte estructural de la naturaleza humana podrían verse excluidas de la condición de ser humano para efectos prácticos sin que medie una justificación sólida y objetiva que no dependa de una simple valoración generalizada. Según lo expuesto por Williams en este sentido (1995, pp. 196-199), una persona incapaz de ejercer la sociabilidad o la razonabilidad práctica al encontrarse, por ejemplo, en un estado comatoso podría ser excluida del género humano para efectos del razonamiento práctico, por cuanto este tipo de personas habrían sido privadas de algunos de los rasgos esenciales que han sido tradicionalmente valorados como característicos entre los individuos de la especie humana. En estos términos, el profesor británico parece reiterar la necesidad, imposible de suplir contemporáneamente, de un PA que sirva de sustento neutral y objetivo para fundamentar apropiadamente cualquier propuesta moral, incluida la ética aristotélica.

A pesar de todo esto, parece razonable afirmar que una interpretación evaluativa de la propuesta ética de Aristóteles no necesariamente sugiere una comprensión categórica y excluyente de la naturaleza humana. En este sentido, interpretaciones contemporáneas del Estagirita apuntan a señalar que su propuesta ética adopta un carácter esencialmente inclusivo, de modo que Aristóteles no restringe la evaluación de lo propiamente humano al ejercicio de unas pocas capacidades relacionadas con el campo del intelecto, la razón práctica o la sociabilidad. Por el contrario, la noción de naturaleza humana para Aristóteles supondría un entendido más amplio de lo humano cuya aproximación a los problemas éticos no se estructura en términos de exclusión, sino sobre la base de que los seres humanos comparten ciertas esferas de experiencia, como la conciencia acerca de la muerte o la necesidad de la distribución de los bienes sociales, que los llevan a pensar su vida en términos éticos y morales (Nussbaum, 1993, pp. 278 y ss.).

Siguiendo esta perspectiva aristotélica, Nussbaum (2007, pp. 160 y ss.) ha argüido que personas imposibilitadas para el ejercicio del razonamiento práctico o la sociabilidad aún pueden ser consideradas como parte de nuestras consideraciones éticas. Lo anterior, toda vez que este tipo de personas 
comparten con el resto de los individuos de la especie humana, además de ciertas funciones básicas en términos biológicos, la experiencia humana relativa a la eventual disminución de capacidades como el intelecto, la razonabilidad práctica o la sociabilidad durante etapas de la vida como la vejez, la niñez o la enfermedad. Por ende, la propuesta práctica del Estagirita, al menos desde una interpretación inclusiva de su concepción de la naturaleza humana, no parece en principio susceptible de sucumbir ante los señalamientos de Williams en el sentido de tornarse en una propuesta arbitrariamente excluyente en términos prácticos. Por lo tanto, resulta todavía plausible el análisis aristotélico de los asuntos éticos, aunque su valoración de lo propiamente humano no necesariamente tenga la pretensión de constituir una descripción universal e indiscutible de la naturaleza humana.

\section{Conclusiones}

Resulta claro que Williams ha presentado una aparente robusta línea argumentativa que trata de poner en tela de juicio la plausibilidad contemporánea del razonamiento ético de Aristóteles. Con tal propósito, el autor británico desarrolló una crítica dirigida a cuestionar el supuesto intento aristotélico de establecer una relación casi científica entre el concepto de naturaleza humana y la noción de eudaimonía. Asumiendo la interpretación de la que se vale el filósofo inglés, el Estagirita se habría equivocado al pretender justificar su análisis de los problemas éticos sobre la base de una descripción de los seres humanos en términos neutrales y objetivos cuya caracterización se asimilaría a la fórmula que emplearía un científico cuando busca describir el universo en términos absolutos e indiscutibles. En opinión de Williams, semejante perspectiva del razonamiento práctico sería totalmente inviable hoy en día, por cuanto el pluralismo propio de la vida contemporánea parece haber desdibujado para siempre la posibilidad de postular una sola noción de felicidad que sea compartida por todos los seres humanos como algo indiscutible.

Sin embargo, la estructura argumentativa empleada por el autor inglés está construida sobre la base de una cuestionable interpretación de la obra aristotélica en relación con los fundamentos del razonamiento ético. En efecto, Bernard Williams asume, probablemente de manera precipitada, que la intención del Estagirita siempre fue proporcionar una definición absoluta de la naturaleza humana con el fin de cimentar sólidamente su análisis de la vida práctica. Con todo, el razonamiento de Aristóteles, siendo un asunto fundamentalmente ligado al campo de la práxis y más bien ajeno al mundo de la 
phýsis, parece estar construido sobre una noción de lo humano que no pretende ser una descripción del universo en términos casi científicos, de modo tal que el concepto de eudaimonía descansa sobre una propuesta evaluativa acerca de los rasgos que podríamos considerar más relevantes en la experiencia vital de los seres humanos. Por mejor decir, la propuesta de Aristóteles en términos prácticos carece de la ambición científica e irrefutable que le atribuye Williams, por cuanto una interpretación más elaborada del pensamiento aristotélico permite entrever el hecho de que los argumentos detrás del concepto de eudaimonía no pretenden tener los alcances definitivos y absolutos que les endilga el pensador británico.

Así las cosas, aun cuando Aristóteles se comprometa abiertamente con una cierta forma de entender la noción de naturaleza humana y con ella la mejor forma posible de vida para los seres humanos, su ética podría aceptar la posibilidad de que las ideas sobre la felicidad o el bienestar no hacen parte de una descripción incontrovertible de la realidad, sino que, por el contrario, son producto de los juicios de valor sobre aquello que normalmente estimamos como esencialmente humano. Teniendo en cuenta todo lo anterior, la propuesta ética del Estagirita, pese a tener como telón de fondo cierta comprensión e interpretación de la naturaleza humana, podría superar la crítica desarrollada por Bernard Williams en Ethics and the Limits of Philosophy (2011). En este sentido, la perspectiva aristotélica en torno al problema ético se erige actualmente como un marco conceptual plausible para dar cuenta de las preguntas sobre el razonamiento práctico de los seres humanos, de manera tal que las nociones de eudaimonía, sabiduría práctica y excelencia pueden seguir siendo importantes en el intento humano por dar un sentido razonable al desenvolvimiento de la vida práctica.

\section{Referencias}

Ackrill, J. L. (1980). Aristotle on Eudaimonia. Rorty A. (Ed.), Essays on Aristotle's Ethics (pp. 15-34). Berkeley: University of California Press.

Aristóteles. (1985). Ética Nicomáquea - Ética Eudemia. (Trad. J. Palli Bonet). Madrid: Gredos.

Berti, E. (2008). Las razones de Aristóteles. (Trad. Horacio Gianneschi \& Maximiliano Monteverdi). Buenos Aires: Oinos. 
Cassirer, E. (1963). Antropología filosófica. (Trad. E. Ímaz). México Fondo de Cultura Económica.

Dancy, J. (2004). Ethics without Principles. Oxford: Oxford University Press.

Foucault, M. (1999). Estrategias de poder. Obras esenciales, Vol. II (pp. 5781). Barcelona: Paidós.

Hobbes, T. (1996). Leviathan. Oxford: Oxford University Press.

Hume, D. (1998). Of the Dignity or Meanness of Human Nature. Selected Essays (pp. 43-49). Oxford: Oxford University Press.

Hursthouse, R. (1991). Virtue Theory and Abortion. Philosophy and Public Affairs, 20(3), pp. 223-246.

Hurley, S. (1993). Objectivity and Forms of Life. Nussbaum, M.C. \& Sen, A. (Eds.), The Quality of Life (pp. 270-276). Oxford: Oxford University Press.

Hutchinson, D. S. (1995). Ethics. J. Barnes (Ed.), Cambridge Companion to Aristotle (195-232). Cambridge: Cambridge University Press.

Kraut, R. (2016). Aristotle's Ethics. Revisado 2 de Abril de 2016, en: http:// plato.stanford.edu/entries/aristotle-ethics/

Lear, J. (1988). Aristotle: The Desire to Understand. Cambridge: Cambridge University Press.

McDowell, J. (1998). The Role of Eudaimonia in Aristotle's Ethics. Mind, Value and Reality (pp. 3-22). Cambridge: Harvard University Press.

Mill, J. S., (1985). Nature. J. M. Robson, F. E. L. Priestley y D. P. Dryer (Eds.), The Collected Works of John Stuart Mill, Volume X - Essays on Ethics, Religion, and Society (pp. 373-402). London: University of Toronto Press and Routledge and Kegan Paul.

Nagel, T. (1980). Aristotle on Eudaimonia. Rorty A. (Ed.), Essays on Aristotle's Ethics (pp. 7-14). Berkeley: University of California Press.

Nussbaum, M. C. (1993). Non-Relative Virtues: An Aristotelian Approach. Nussbaum, M.C. \& Sen, A. (Eds.), The Quality of Life (pp. 242-270). Oxford: Oxford University Press. 
Nussbaum, M. C. (1995). Aristotle on human nature and the foundations of ethics. Altham, J. \& Harrison, R. (Eds.), World, Mind, and Ethics: Essays on the Ethical Philosophy of Bernard Williams (pp. 86-131). United States: Cambridge University Press.

Nussbaum, M. C. (2007). Frontiers of Justice: Disability, Nationality, Species Membership. Cambridge: Harvard University Press.

Prichard, H. A. (1912). Does Moral Philosophy Rest on a Mistake? Mind, Vol. 21 (81), pp. 21-37.

Ross, D. (1995). Aristotle. New York: Routledge.

Rorty, R. (1989). Contingency, Irony and Solidarity. Cambridge: Cambridge University Press.

Sandel, M. (2011). Justicia: ¿Hacemos lo que debemos? (Trad. J. P. Campos Gómez). Barcelona: Debate.

Stevenson, L. \& Haberman, D. (1998). Ten Theories of Human Nature. Oxford: Oxford University Press.

Scheler, M. (1994). El puesto del hombre en el cosmos. Buenos Aires: Editorial Losada.

Williams, B. (1995). Replies. Altham, J. \& Harrison, R. (Eds.), World, Mind, and Ethics: Essays on the Ethical Philosophy of Bernard Williams (pp. 185-224). Cambridge: Cambridge University Press.

Williams, B. (2011). Ethics and the Limits of Philosophy. London: Routledge. 